\title{
An Insight into Actual Energy Use and Its Drivers in High-Performance Buildings
}

\author{
Cheng Li, ${ }^{a}$ Tianzhen Hong, ${ }^{a}$ * Da Yan ${ }^{b}$
}




\section{Abstract}

Using portfolio analysis and individual detailed case studies, we studied the energy performance and drivers of energy use in 51 high-performance office buildings in the U.S., Europe, China, and other parts of Asia. Portfolio analyses revealed that actual site energy use intensity (EUI) of the study buildings varied by a factor of as much as 11, indicating significant variation in real energy use in HPBs worldwide. Nearly half of the buildings did not meet the American Society of Heating, Refrigerating, and Air Conditioning Engineers (ASHRAE) Standard 90.1-2004 energy target, raising questions about whether a building's certification as high performing accurately indicates that a building is energy efficient and suggesting that improvement in the design and operation of HPBs is needed to realize their energy-saving potential. We studied the influence of climate, building size, and building technologies on building energy performance and found that although all are important, none are decisive factors in building energy use. EUIs were widely scattered in all climate zones. There was a trend toward low energy use in small buildings, but the correlation was not absolute; some small HPBs exhibited high energy use, and some large HPBs exhibited low energy use. We were unable to identify a set of efficient technologies that correlated directly to low EUIs. In two case studies, we investigated the influence of occupant behavior as well as operation and maintenance on energy performance and found that both play significant roles in realizing energy savings. We conclude that no single factor determines the actual energy performance of HPBs, and adding multiple efficient technologies does not necessarily improve building energy performance; therefore, an integrated design approach that takes account of climate, technology, occupant behavior, and operations and maintenance practices should be implemented to maximize energy savings in HPBs. These findings are intended to help architects, engineers, operators, and policy makers improve the design and operation of HPBs. 


\section{Introduction}

Worldwide concern about depletion of non-renewable energy sources and anthropogenic climate change has accelerated in recent years [1,2]. Energy use in buildings accounts for one-third of the world's total primary energy consumption and contributes significantly to greenhouse gas (GHG) emissions [3-5]. With growing consciousness of the need to save energy in buildings, high-performance buildings (HPBs) (a.k.a. green, sustainable, or low-energy/low-carbon buildings) have emerged around the world as an important component of efforts to reduce energy use and global GHG emissions [4, 5].

As HPB initiatives have been extensively implemented by energy-conscious architects, engineers, and governments [6-9], a variety of rating systems have been developed to certify the performance of these buildings.

These rating systems, such as the U.S. Green Building Council's (USGBC's) Leadership in Energy and Environmental Design (LEED) system [11] and the Three Star rating system in China, assign credits for various indicators [10] and thus directly influence the design of HBPs. These rating systems have also had a stimulating effect on the HPB market. Figure 1 (a), which is based on data from the USGBC [12], shows that more than 1,000 LEED-certified buildings are constructed worldwide per year. Figure 1 (b) shows that, in China, the largest construction market in the world, HPBs are enjoying exponential growth. These data indicate the major impact of HPBs on the building industry.

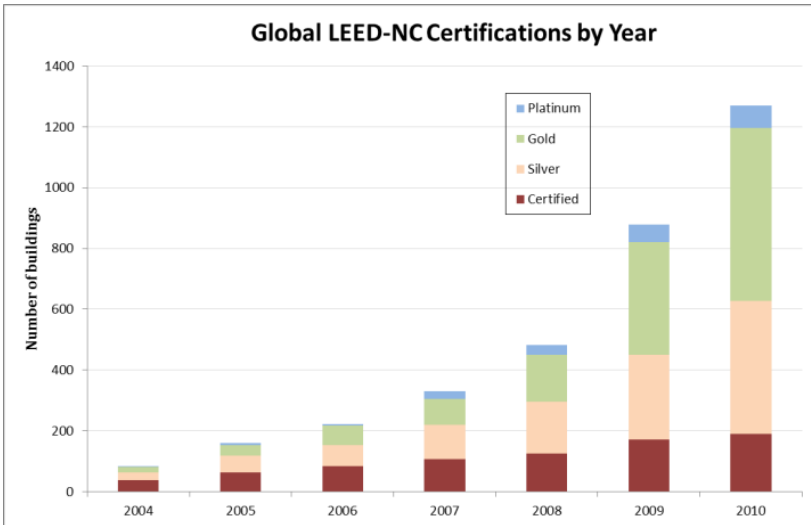

(a) Worldwide Number of LEED-New Construction (NC) certified buildings

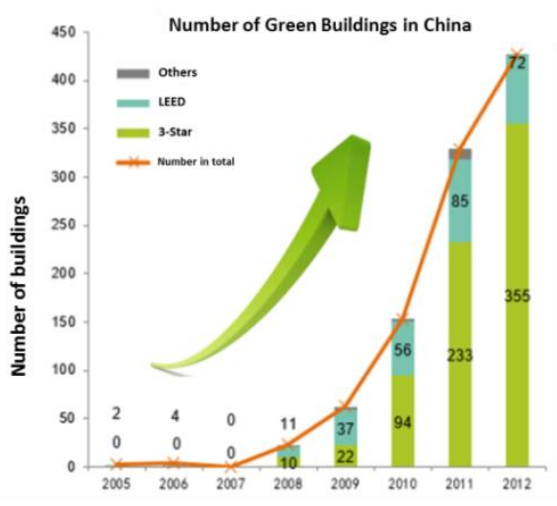

(b) Growth of green buildings in China [13]

\section{Figure 1. Growth in green buildings, globally and in China}

Many certified HPBs have already been occupied for a number of years, offering researchers the opportunity to evaluate the buildings' actual performance rather than the simulated results on which ratings and certifications are based [10, 13-19]. In 2008, the U.S. General Services Administration (GSA) conducted a postoccupancy evaluation to determine the actual performance of their green buildings. Actual energy use, $\mathrm{CO}_{2}$ emissions, water use, and occupant satisfaction were studied in 12 representative GSA green buildings [20, 21]. Results showed that these buildings generally outperformed their conventional peers in these areas. 
Although actual energy use is the most reliable indicator of the success of HPBs, all current rating systems for newly constructed HPBs base certification on predicted energy savings that are calculated by simulation tools based on a building's proposed design compared to a baseline design that meets minimum code requirements. However, multiple studies report gaps between designed and actual energy consumption in HPBs, including a 2004 report by the National Renewable Energy Laboratory [17], 2006 research by Diamond [18], and 2012 research by the University of California, Santa Barbara [22]. These prior studies indicate that actual energy consumption is the most meaningful metric for evaluating the performance of HPBs.

Turner's 2006 analysis collected information on 11 LEED buildings in the northwestern United States (the cities of Seattle and Portland) and compared their actual energy use, designed energy targets, and baseline energy use [16]. The actual energy use deviates from the simulated performance by more than $20 \%$ for all the buildings; and the actual energy use in $40 \%$ of the buildings was greater than designed or simulated. The extent of the discrepancy between predicted and actual energy use in these buildings was as high as 2. Likewise, Diamond reviewed actual and simulated energy performance of 21 LEED-certified buildings [18]. Actual energy use of the buildings was, on average, only $1 \%$ lower than simulated performance, but large variability (standard deviation of 46\%) in the sample set highlighted a remarkable disparity in performance among buildings. This research suggests that there can be a significant inconsistency in performance among HPBs that have the same level of certification.

In 2008, the New Buildings Institute (NBI) analyzed utility billing data for 121 LEED-certified commercial buildings. This study concluded that LEED buildings in the U.S. generally saved 25-30\% compared to energy usage in conventional buildings [19]. However, this study has been heavily criticized for its methodology and conclusions. Critics argued that the study's data collection methods were likely to result in biased sampling and that the study's analysis approach resulted in misunderstanding regarding sources of energy consumption and carbon emissions $[23,24]$. The study was also criticized for drawing conclusions based on simple comparison of the median EUI of LEED buildings to the mean EUI of all U.S. commercial buildings without any statistical tests. Guy et al. argued that the average trends in the NBI study might be spurious [25].

Despite the controversy regarding approach and metrics used in the NBI study, there is no question about the value of that analyzing HPB energy performance and it is clear that the large variability among EUIs in HBPs worldwide needs to be studied. And even though the NBI study concluded that LEED-certified buildings are generally saving energy, the NBI analysis results (Figure 2) do not support the conclusion that LEED buildings consistently deliver expected energy savings. Figure 2, shows that EUIs of NBI study buildings at 
every certification level are scattered by a factor of up to 4, and buildings with EUIs greater than those of conventional buildings are found throughout all three LEED certification levels (The Gold and Platinum levels are combined in Figure 2). Although the average energy consumption of the buildings at each of the three LEED certification levels is lower than the average of commercial buildings in the 2003 Commercial Buildings Energy Consumption Survey (CBECS) database, a significant number of buildings nonetheless consume more site energy than the average for commercial buildings in the CBECS database. In tandem with these results, media reports of buildings that do not live up to their green labels threaten the credibility of HPBs [26-28]. In sum, although the general or average performance of HPBs might be acceptable, the evidence does not support the conclusion that all high-performance-certified buildings reliably live up to their predicted energy performance or that the current approaches to HPB design and rating dependably result in highly energy-efficient buildings.

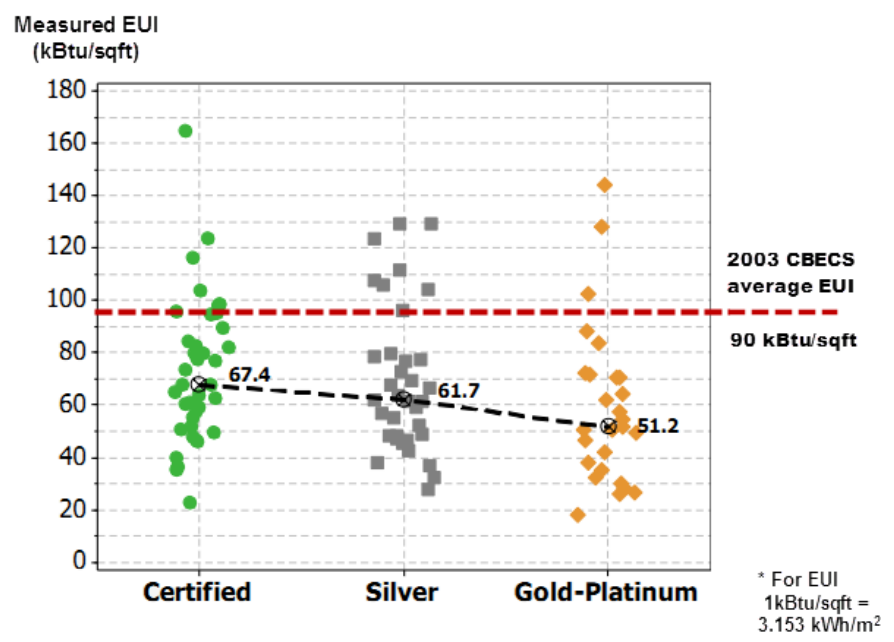

Figure 2. Profile of measured energy use for 100 U.S. LEED-NC-certified buildings [19]

In light of the research we have summarized, we hypothesize that the underlying driving forces of the diverse performance of HPBs are more important to study than holistic or average performance to determine the improvements needed to guarantee the energy performance of HPBs. Therefore, this study analyzes the energy use of HPBs along with the factors that influence energy use, with the goal of empowering designers to improve the energy performance of HPBs.

It is important to note that all of the abovementioned research was performed on LEED buildings in the U.S. although LEED is only one rating system that happens to have been widely promoted and adopted.

Globally, HPBs have been promoted and certified under various rating systems, including the Building Research Establishment Environmental Assessment Methodology (BREEAM) in the UK [29], the Comprehensive Assessment System for Built Environment Efficiency (CASBEE) in Japan [30], Deutsche Gesellschaft für 
1 Natchhaltiges Bauen (DGNB) in Germany [31], and Three Star in China [32]. Therefore, ours has a global scope to enable us to learn from HPBs constructed under varying rating systems.

Although energy performance of buildings has been studied extensively using building simulations [33] to identify and understand driving factors [34], there is significant uncertainty associated with these simulations and their accuracy in predicting actual performance. Therefore, we used portfolio analysis and case studies for our investigation.

The primary goals of the current study are to provide insight into the diverse actual energy performance of HPBs as well as the factors that influence energy consumption in HPBs around the world and to make recommendations for improving building energy performance during design, operation, and retrofit. We set out to address the following important questions about HPBs:

1. What is the current status quo actual energy performance of HPBs globally?

2. What energy-saving technologies are commonly employed in HPBs?

3. Does the inclusion of more technologies in buildings result in low energy use?

4. What factors drive HPB energy performance?

5. What practices guarantee good energy performance?

The remainder of this paper is organized as follows. First, we describe our research methodology. Next, we describe the current energy performance of the study HPBs and analyze factors that are commonly believed to drive energy performance. Finally, based on detailed data from two HPBs, we analyze occupant behavior and operation and maintenance $(\mathrm{O} \& \mathrm{M})$ practices to determine their influence on energy performance.

\section{Methodology}

To answer the five questions listed above, we performed portfolio analysis and prepared detailed case studies of the energy use of $51 \mathrm{HPBs}$ around the world.

\subsection{Building selection}

Based on our research goals, we chose our study building by focusing on energy consumption, the presence of energy-related technologies, and other relevant information. All analyses were based on measured wholebuilding energy consumption from at least one year. The performance metric used in this study was site energy use before any on-site renewable energy generation was taken into account. Although it is considered controversial whether site energy consumption can represent a building's essential performance in terms of energy and GHG emissions [23, 24], engineers and architects commonly think of the energy savings in terms of 
site energy [35]. Also, it is much easier to compare building performance with site energy use, which can be directly measured and is not affected by how primary or source energy is calculated, which is location dependent. Therefore, to facilitate holistic comparison, we used site EUI, defined as the annual site energy use divided by the gross floor area of the building excluding the garage and basement floor area. The site energy includes the whole building's electricity and gas consumption for a complete year. For buildings with district heating (mostly the China buildings), the heating energy is converted and included in site energy assuming an average heating efficiency during a heating season.

Buildings with different functions tend to exhibit different energy performance; for example, hospitals consume much more energy than other types of buildings because of their heavy process loads, intensive ventilation, and longer operating hours. Therefore, energy portfolio analysis should focus on one building type at a time. Based on the distribution of all the newly constructed HPBs, we chose to focus on office buildings, which dominate in social energy consumption profiles and will likely dominate the construction market in the near future.

Different regions are pursuing the HPB concept in different ways. With our goal of expanding the study of HPBs to a global scale, we chose to focus on the U.S., Europe, and Asia-Pacific region, based on the extent of HPB development and the rating systems in these regions as well as the dominance of these regions in the global construction market. In particular, China is emerging as a major contributor to global building construction and energy consumption.

The HPBs in this study met the following criteria. They are:

1. newly constructed and occupied office buildings,

2. located in the U.S., Europe, China, or the Asia - Pacific region,

3. with at least one complete year of site energy use records and information on total floor area to enable calculation of actual EUI, and

4. a high level of performance certification, such as LEED Platinum or Gold, CASBEE "S," or China Three-Star.

Our data sources were:

1. The United States Department of Energy (U.S. DOE) Building database, http://buildingdata.energy.gov/

2. The U.S. DOE Building Performance database, http://www1.eere.energy.gov/buildings/commercial/bpd.html

3. The NBI database, http://buildings.newbuildings.org/index.cfm

4. The Lawrence Berkeley National Laboratory building database "Energy IQ," http://energyiq.lbl.gov/ 


\section{Books on HPBs: the World's Greenest Buildings [35] and China Green Buildings [36]}

Thanks to our partners, Shenzhen Institute of Building Research co. Itd (IBR), the California State

Teachers' Retirement System (CalSTRS), and Tsinghua University, energy end-use breakdowns for some HPBs were available for detailed performance analysis and benchmarking.

HPB certification is a good criterion for classifying buildings enabled us to narrow the scope of our research.

We selected buildings with the highest ratings from the following seven rating systems:

- $\quad$ LEED-NC Gold and Platinum (U.S., China, India, and other countries)

- $\quad$ BREEAM Excellent and Outstanding (UK)

- $\quad$ Six-Star Green Star (Australia)

- $\quad$ Green Mark Platinum (Singapore)

- CASBEE “S” (Japan)

- $\quad$ DGNB Certified Gold (Germany)

- Three-Star Green Building Certification (China)

We chose buildings with the highest ratings even though, as we have outlined earlier, the common perception that higher levels of building certification indicate better energy performance has been shown to be incorrect. We chose highly rated buildings precisely because we wanted to understand the differences in driving factors influencing the energy performance of buildings that had been given high levels of certification.

Using the criteria listed above, we selected $51 \mathrm{HPBs}$ for this study. Figure 3 shows the geographic distribution of the buildings. We compiled information about the buildings into a database, including total floor area, EUI, climate zone, and efficient technologies. We studied global and regional EUI profiles to establish the current range of energy performance in HPBs.

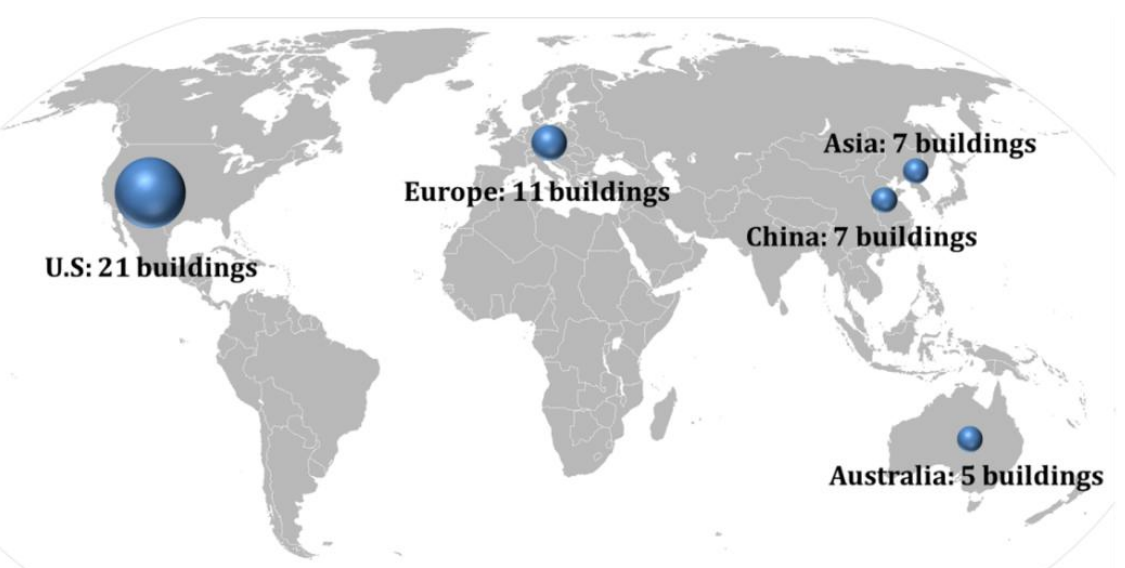

Total: 51 Buildings 


\subsection{Analysis methods}

We used two methods to answer the questions raised in the introduction to this article. Portfolio analysis was used to examine the holistic profile of the buildings' energy performance as well as factors influencing energy consumption: climate, building size, and installed technologies. Benchmarks were used to determine building performance compared to U.S. existing commercial buildings as well as ASHRAE Standard 90.1 energy targets. According to the International Energy Agency (IEA) Energy Conservation in Buildings and Community Systems Annex 53, Total energy use in buildings - assessment and analysis methods [37], energy performance of buildings is driven by six factors: climate, building envelope, building equipment (energy service systems), O\&M, occupant behavior, and indoor environmental conditions, as shown in Figure 4. We designed group comparisons to reveal the relationship between building energy performance and these factors. We performed detailed analysis of two individual buildings, based on measured performance data and on-site surveys and interviews with building operators and occupants, to understand the influence of occupant behavior and O\&M on energy use.

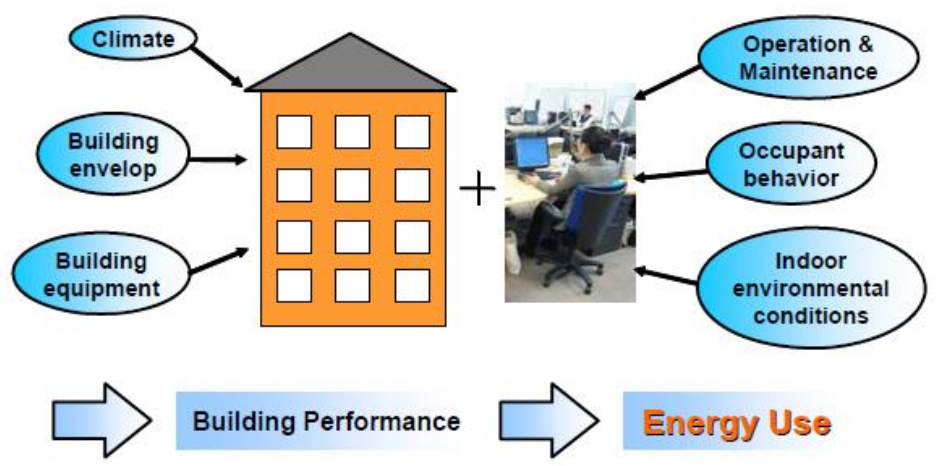

Figure 4. Six factors that influence energy use in buildings [37]

\section{Portfolio analysis of energy consumption and driving factors}

The subsections below describe our analysis of energy consumption and its driving factors in the 51 highperforming office buildings.

\subsection{Variation in energy performance}

Figure 5 presents an overall picture of energy performance of the 51 study buildings by showing the EUIs from lowest to highest. Each colored bar represents the EUI of an individual building, and bars are color coded based on each building's location to indicate the regional distribution. Four horizontal lines represent four benchmark EUIs: (1) the average EUI of the office buildings in the 2003 CBECS database [38], (2) the median EUI of the office buildings in the 2003 CBECS database, and (3) the overall EUI target for office buildings 
meeting minimum requirements of ASHRAE standard 90.1-2004 [39], and (4) the overall EUI target for office buildings meeting minimum requirements of ASHRAE standard 90.1-2010 [40, 41].

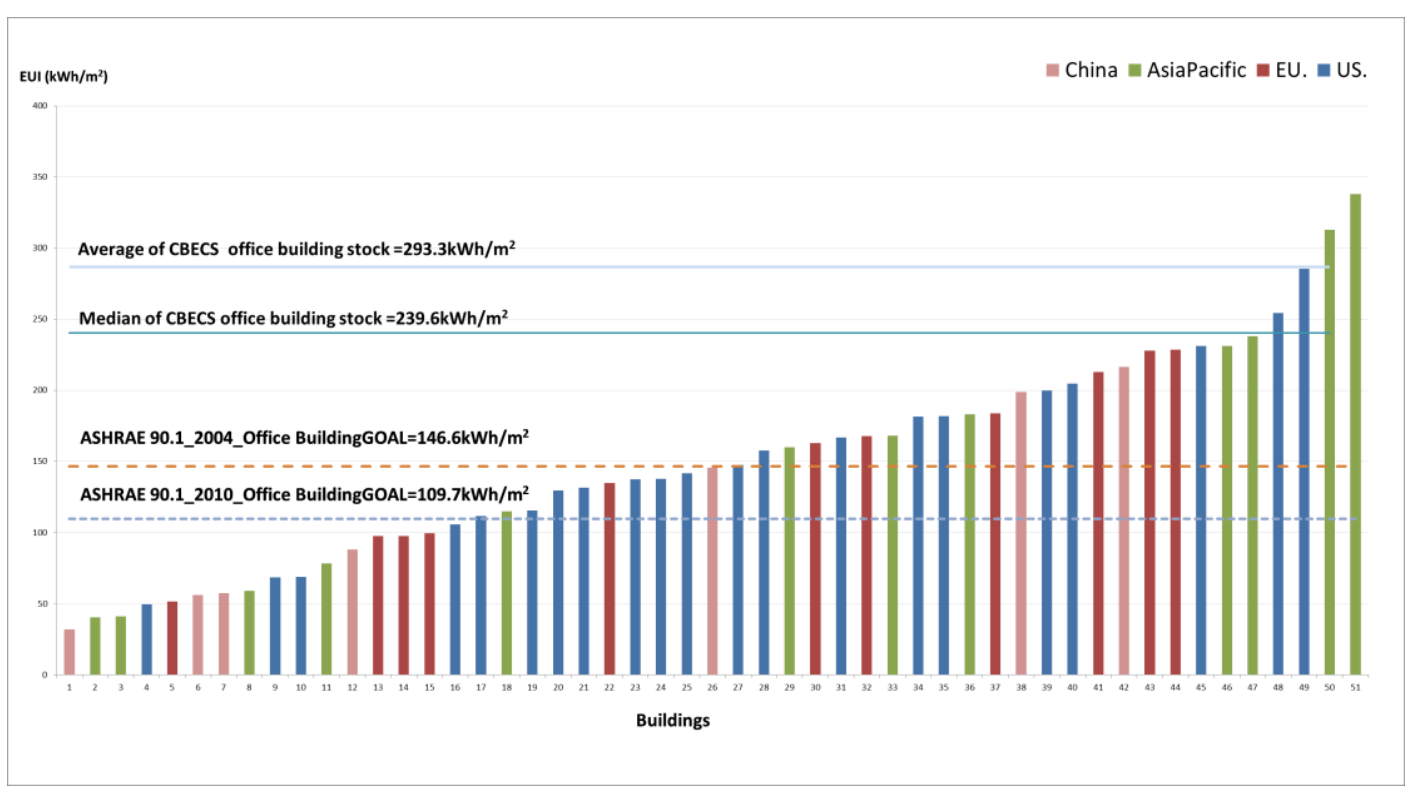

Figure 5. Distribution of site EUIs of the 51 study buildings, compared to benchmarks

Figure 5 shows that EUIs vary from 30 to $330 \mathrm{kWh} / \mathrm{m}^{2}$, i.e., by a factor of as much as 11 . This scattering of EUIs indicates that even though the buildings are all of the same type (office) and have similar certification, their energy performance varies substantially. Most HPBs in this study showed better energy performance than the average and median EUI of office buildings in the 2003 CBECS database. However, four buildings performed worse than the median. Therefore, we conclude that an overall high performance rating of a building does not directly correlate to low energy use.

The median EUI in the data set is $145.7 \mathrm{kWh} / \mathrm{m}^{2}$, which is slightly lower than the ASHSRAE 90.1-2004 energy target of $146.6 \mathrm{kWh} / \mathrm{m}^{2}$. This means that, in our data set, only $50 \%$ of the buildings meet a relatively outdated target, the 2004 ASHRAE standard. When we compare the buildings' performance to a more aggressive goal, the ASHRAE 90.1-2010 energy target of $109.7 \mathrm{kWh} / \mathrm{m}^{2}$, the compliance rate drops sharply to $30 \%$. This statistic indicates that most HPBs exhibit relatively poor actual energy performance and suggests that more emphasis should be placed on the actual energy use of HPBs to ensure actual energy savings. For example, importance of actual energy performance should be emphasized in the next generation of rating systems and regulations or codes for HPBs, such as LEED for Existing Building Operation \& Maintenance (EBOM) [42].

To investigate variations in EUI by country, we grouped the 51 study buildings into three geographic subcategories: the U.S., Europe, China, and the Asia-Pacific region. Figures 6 through 8 illustrate the distribution 
1 of EUIs in each of these countries or regions. The median and average EUIs and the energy target of ASHRAE 2 90.1-2004 are indicated in all of the figures.

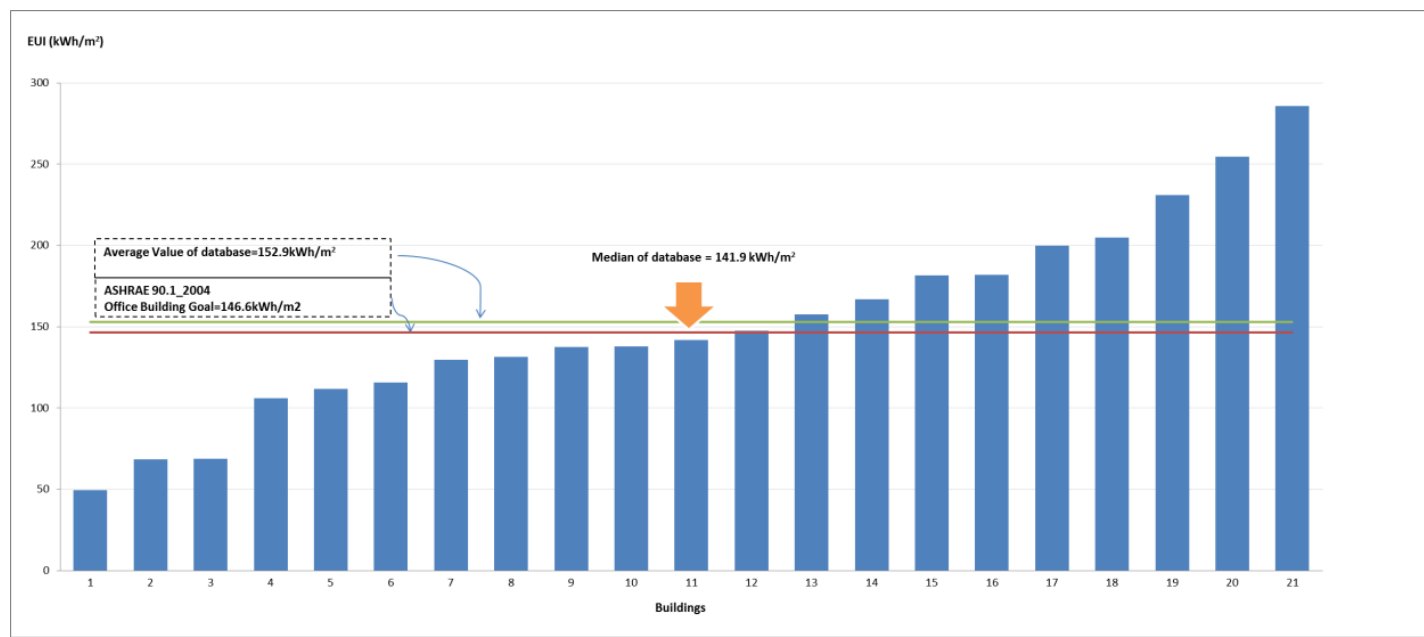

Figure 6. Distribution of site EUIs for HPBs in the U.S.

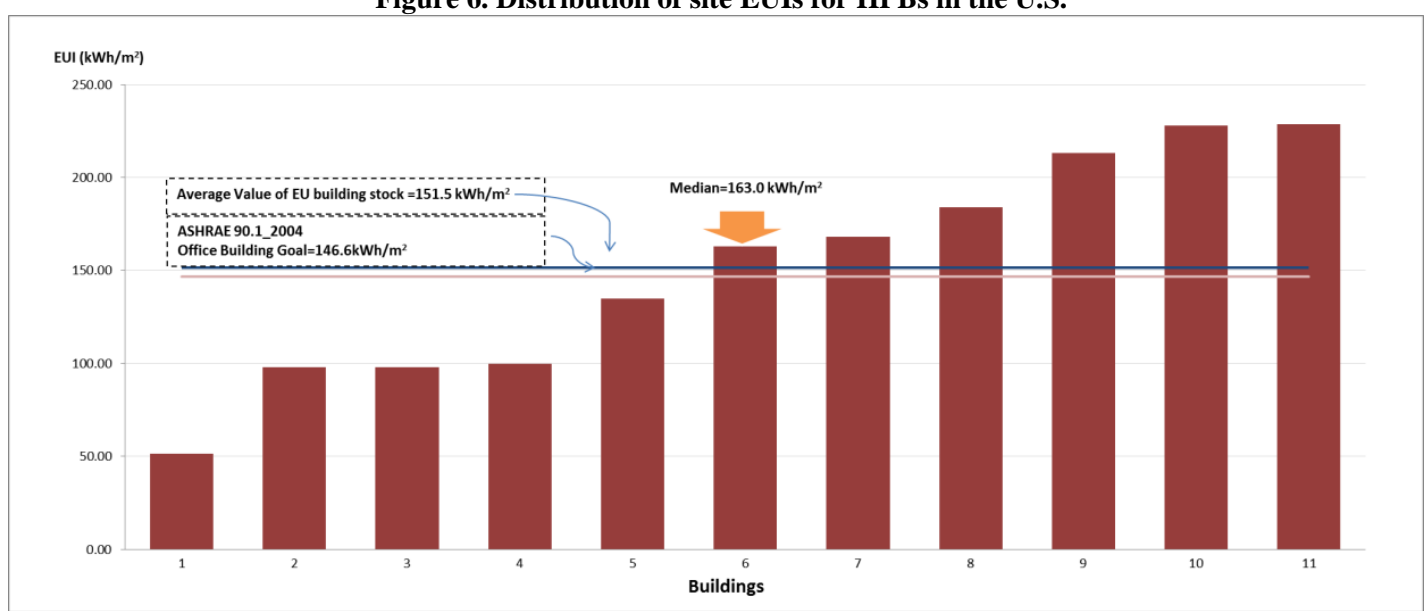

Figure 7. Distribution of site EUIs for HPBs in Europe

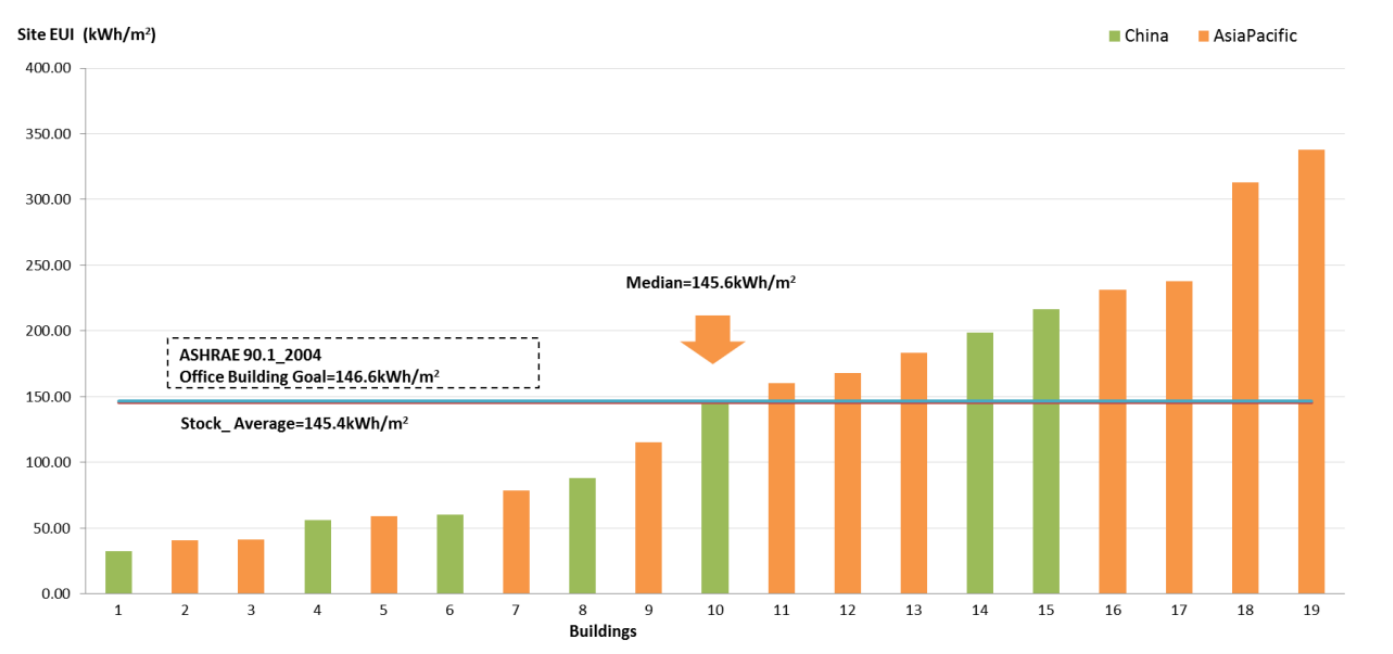

Figure 8. Distribution of site EUIs for HPBs in China and the Asia-Pacific region

Figures 6, 7 and 8 show that EUIs are widely scattered in all three regions. The variation in EUIs ranges

from 4 for European buildings to 6 for U.S. buildings to 11 for buildings in the Asia-Pacific region and China, as 


\begin{tabular}{cccc}
\multicolumn{4}{c}{ Table 1. Characteristics of site EUI for high-performance buildings in three regions } \\
\hline & $\begin{array}{c}\text { Scale of Variation of EUI } \\
\text { (Highest/Lowest) }\end{array}$ & $\begin{array}{c}\text { Average EUI } \\
\left(\mathbf{k W h} / \mathbf{m}^{\mathbf{2}}\right)\end{array}$ & $\begin{array}{c}\text { Median EUI } \\
\left(\mathbf{k W h} / \mathbf{m}^{\mathbf{2}} \mathbf{)}\right.\end{array}$ \\
\hline U.S. & 6 & 152.9 & 141.9 \\
EU & 4 & 151.3 & 163.0 \\
Asia \& China & 11 & 145.4 & 145.4 \\
\hline
\end{tabular}

shown in Table 1. The median EUI of the buildings from all three regions is very close to the ASHRAE 90.12004 energy target, which implies that in all three regions, only 50\% of HPBs met the ASHRAE target. The average and median EUIs in Table 1 show that the overall performance of buildings is very similar in all three regions. Therefore, we conclude that no particular region or country has HPBs with consistently better energy performance. The combination of widely scattered EUIs and 50\% of buildings falling below the 2004 ASHRAE target indicates that the challenge of guaranteeing that HPBs achieve their designed energy performance is global. To achieve this goal, we must understand the factors that drive the energy performance of HPBs. The analyses in the subsequent sections of this article are designed to identify these factors.

\subsection{Impact of climate}

There is consensus that climate has a significant impact on building energy consumption. Therefore, we investigated the relationship of climate to the EUIs of our study buildings. Climate is typically treated as an independent parameter in regressions of energy performance using heating and cooling degree days [43]. Abundant weather data are needed to quantitatively analyze the impact of climate on energy consumption. Because weather data were lacking for the 51 buildings in this study, we simply categorized EUI data according to the buildings' climate zones as defined in ASHRAE Standard 90.1. This method was also used in the NBI report [19]. Following the approach used in the NBI report, we grouped the climates of the 51 buildings into four types. Figure 9 shows the interquartile box and the scattering range of the EUIs based on that classification. The X-axis in Figure 9 represents four climate types: warm-hot, mixed, cool, and cold. The corresponding ASHRAE climate code is listed below each zone, along with the range of floor area in each climate zone. The red bar in the interquartile boxes denotes the median value, and the colored arrow points out the average value of every corresponding group of buildings. The ASHRAE 90.1-2004 target (EUI of $146.6 \mathrm{kWh} / \mathrm{m}^{2}$ ) is indicated as a horizontal green dashed line for benchmarking purposes. 


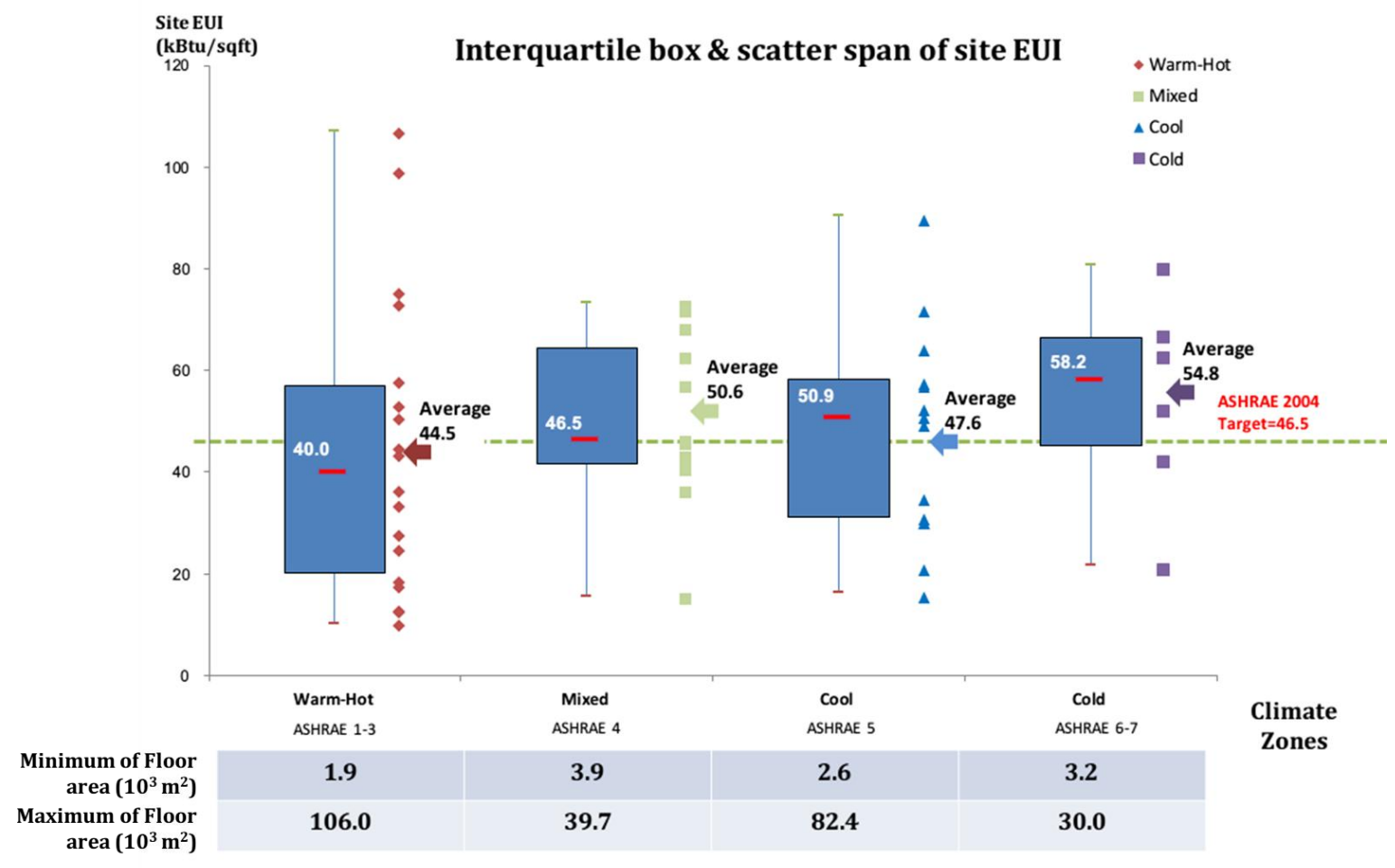

Figure 9. Distribution of site EUIs among four climate zones

From the viewpoint of overall performance, i.e., median and average values, the EUI of HPBs in the warmhot zone is lower than that of HPBs in the other zones as well as exceeding the ASHRAE 90.1-2004 target. The reasons for this are the likely absence of space heating and the widespread use of natural ventilation in this climate zone. Although the overall performance appears satisfactory, the EUIs in this zone are widely scattered ranging from approximately 47.3 to $346.8 \mathrm{kWh} / \mathrm{m}^{2}$; this is the largest spread of values among the four climate zones. Even though this climate zone has the largest number of HPBs, buildings with EUIs greater than the ASHRAE 90.1-2004 target account for half of the stock in this zone. The average EUI is slightly lower than the AHSRAE 2004 target.

As noted above, scattered EUI values are found in all of the climate zones. From the mixed zone to the cold zone, no more than 50\% of the HPBs performed better than the ASHRAE 90.1-2004 target. The EUIs of the poorly performing buildings increase the average EUI value for each zone. As a result of the scattered EUI values and large numbers of buildings that fall short of the ASHRAE target, the overall energy performance in the mixed, cool, and cold zones is worrisome, as shown in Figure 9. And given the large spread of EUIs in every climate zone, we conclude that even if all study buildings were located in the same climate, they would exhibit significantly different energy performance, which means that factors other than climate are driving the variation in performance. 
Although median EUIs appear to increase from the hot to cool to cold climate, this is simply a result of our use of site energy use as the performance metric. Site energy reflects cumulative energy consumption from various sources including electricity, natural gas, and other fuels used for space or water heating. When primary or source energy is used as the performance metric, electricity typically carries a much higher (approximately 3 ) factor in the calculation of source energy, which would reverse the trend of buildings in hot climates exhibiting higher EUIs.

\subsection{Impact of building size}

It is commonly assumed that large buildings inherently consume more energy than small ones. To investigate this assumption, we plotted the correlation between floor area and EUI, as shown in Figure 10.

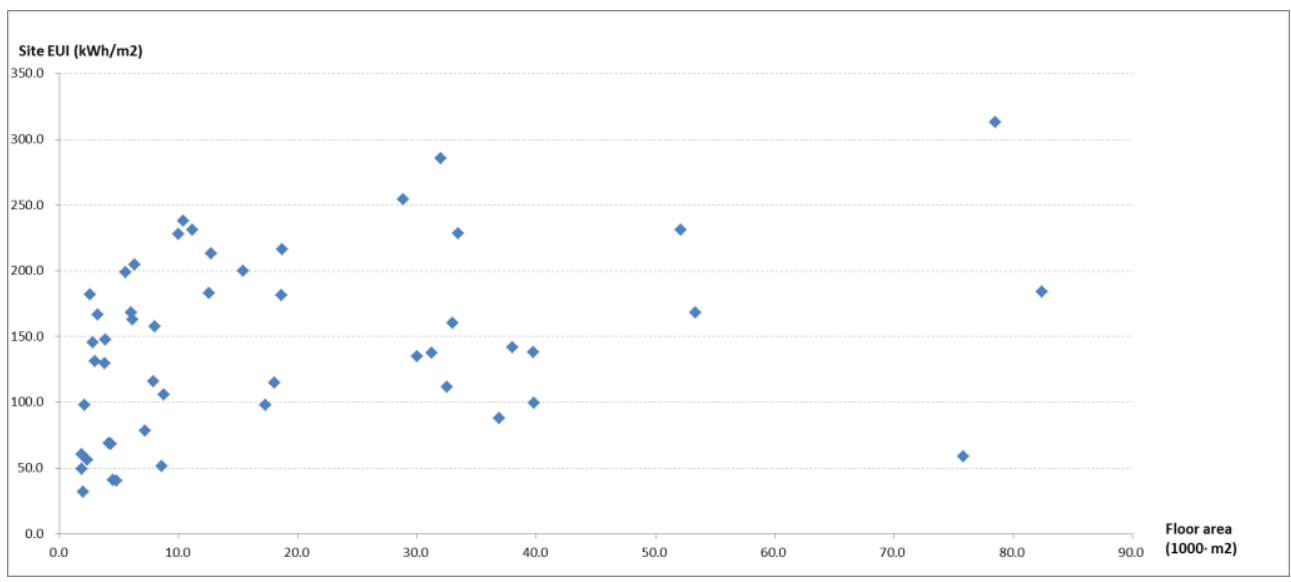

Figure 10. Correlation between floor area and EUI

Figure 10 shows that the correlation between a building's site EUI and its total floor area is very weak.

Among the 51 buildings we studied, the Pearson correlation coefficient between the EUI and floor area is 0.32 , indicating no clear or strong evidence that small buildings will consume less energy than larger ones. However, the small building group has a higher proportion of buildings with relatively lower EUIs than does the large building group. With regard to this trend and the definition of what constitutes a "small" building, Table 2 shows the five categories of floor area and three EUI bands into which we divided our study buildings as well as the proportion of EUIs within each category. The criteria for the floor-area categories and the EUI bands were established by referencing the NBI report.

Table 2. Proportion of site EUI for each floor-area category

\begin{tabular}{|c|c|c|c|}
\hline Sloor area $\left(\mathbf{m}^{\mathbf{2}}\right)$ & $\mathbf{0 - 1 0 0}$ & $\mathbf{1 0 0}-\mathbf{2 0 0}$ & $>\mathbf{2 0 0}$ \\
\hline$<\mathbf{5 , 0 0 0}$ & $60.0 \%$ & $40.0 \%$ & $0.0 \%$ \\
\hline $\mathbf{5 , 0 0 0}-\mathbf{1 0 , 0 0 0}$ & $22.2 \%$ & $66.7 \%$ & $11.1 \%$ \\
\hline $\mathbf{1 0 , 0 0 0}-\mathbf{2 0 , 0 0 0}$ & $10.0 \%$ & $40.0 \%$ & $50.0 \%$ \\
\hline $\mathbf{2 0 , 0 0 0}-\mathbf{5 0 , 0 0 0}$ & $18.2 \%$ & $54.5 \%$ & $27.3 \%$ \\
\hline$>\mathbf{5 0 , 0 0 0}$ & $16.7 \%$ & $33.3 \%$ & $50.0 \%$ \\
\hline
\end{tabular}


Sixty percent of buildings smaller than $5,000 \mathrm{~m}^{2}$ have site EUIs less than $100 \mathrm{kWh} / \mathrm{m}^{2}$, and no building has EUI greater than $200 \mathrm{kWh} / \mathrm{m}^{2}$. Based on the values in Table 2, it appears that buildings smaller than 5,000 $\mathrm{m}^{2}$ have the greatest possibility of achieving very low or zero net energy. For buildings in the 5,000 to $10,000 \mathrm{~m}^{2}$ and 10,000 to $20,000 \mathrm{~m}^{2}$ categories, the proportion of EUIs lower than $200 \mathrm{kWh} / \mathrm{m}^{2}$ is smaller than in the category of buildings smaller than $5,000 \mathrm{~m}^{2}$, and the proportion of EUIs greater than $200 \mathrm{kWh} / \mathrm{m}^{2}$ rises significantly in the two categories of larger buildings, indicating a trend toward more energy use as floor area increases. As the floor area increases, buildings with EUIs greater than $100 \mathrm{kWh} / \mathrm{m}^{2}$ dominate. It is evident that large buildings are much less likely to have low EUIs.

The above holistic view of EUI distribution based on building size shows a general trend that small buildings are more likely to have low EUIs, and large buildings have higher EUIs than small buildings. The function and operation of small buildings are usually simple; small office buildings are typically dominated by offices and meeting rooms, and work schedules in these buildings are typically regular, e.g., 8 hours per day and 5 days per week, which means that energy-consuming equipment is not used at night. In contrast, large buildings are often headquarters or multi-functional complexes in metropolises and may contain large data centers, which are energy intensive and operate continuously. The operating hours of these buildings are usually extended, and most of the fundamental equipment functions during operating hours, which increases energy consumption compared to buildings where most equipment does not function during off hours. Therefore, it is reasonable to assume that large buildings will likely consume more energy than smaller ones. However, it is noteworthy that this is only a general pattern. Some individual large buildings have EUIs lower than $100 \mathrm{kWh} / \mathrm{m}^{2}$. This suggests that it is still possible for a large building to be energy efficient if deliberately designed and operated with this goal in mind.

\subsection{Impact of building technologies}

The subsections below analyze the relationship of building technologies to energy use alone and in relation to climate and building size.

\subsubsection{EUI in relation to building technologies}

In the design of HPBs, much attention is usually paid to "high-performance technologies," such as efficient lighting systems and envelope and heating, ventilation, and air-conditioning (HVAC) efficiency measures. Many assume that these technologies are the crucial factors that determine the building's energy performance.

Advocates of high-performance technologies argue that the main contributor to a building's energy use is energy 
1 consumed by building equipment, so the key to saving energy must be improving equipment efficiency. From

2 this perspective, it appears natural to assume that technologies that maximize equipment efficiency will

3 determine energy savings.

To investigate the above assumptions, we collected data on building technologies and actual building energy consumption. Table 3 shows the technologies installed in each building along with the site EUI. The "Y" in each colored cell stands for "Yes". Buildings are ordered by their EUIs from low to high. All information about technologies was classified into three major categories and sub-classes, as follows:

- Lighting-related technologies: use of daylight, high-efficiency lighting systems, lighting control strategies (e.g., occupancy control, dimming control)

- Envelope technologies: insulation improvement, glazing improvement, and shading technologies

Table 3 also shows on-site renewable energy technologies. For comparison purposes, the table simply lists the presence or absence each technology. The application of a technology is highlighted in pink, and renewable energy applications are colored in green. The bottom row of Table 3 shows the percentage of buildings in our study group in which each technology is installed. 


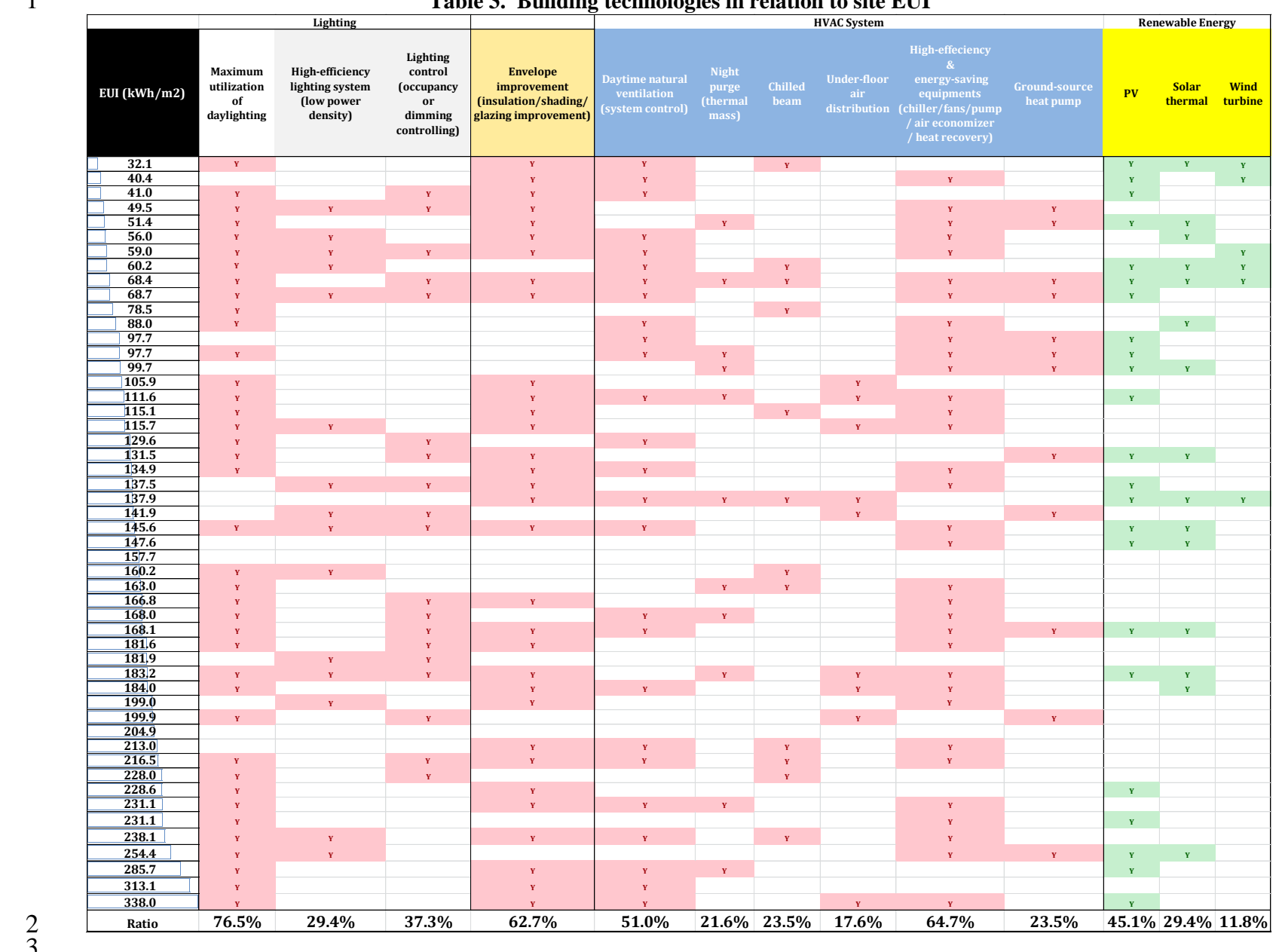

As shown in Table 3, the three energy-efficient technologies most commonly installed in HPBs are

5

daylighting (76.5\%), high-efficiency HVAC systems (64.7\%), and improved envelopes (62.7\%). These technologies are found in buildings with EUIs ranging from low to high. The percentage of buildings containing these three technologies indicates their broad applicability and suitability. However, the widespread deployment of the three technologies, in combination with the widely varying EUIs of the buildings in which they are installed, also unfortunately suggests that there is no direct relationship between the presence of these technologies and building energy use. Given that these technologies appear to be standard in newly constructed HPBs, we suggest that designing and operating the technologies more deliberately that is currently done might be necessary to realize their energy-saving potential.

Table 4 shows the study buildings divided into three groups according to EUI, with the percentage of buildings having each technology calculated separately to determine whether any single technology is linked to low energy use. The EUI ranges are the same as in Table 2, i.e., 100 and $200 \mathrm{kWh} / \mathrm{m}^{2}$. 


\begin{tabular}{|c|c|c|c|c|c|c|c|c|c|c|c|c|c|}
\hline \multirow[b]{2}{*}{$\begin{array}{c}\text { EUI range } \\
(\mathrm{kWh} / \mathrm{m} 2)\end{array}$} & \multicolumn{3}{|c|}{ Lighting } & \multirow[b]{2}{*}{$\begin{array}{c}\text { Envelope } \\
\text { improvement } \\
\text { (insulation/shading/ } \\
\text { glazing } \\
\text { improvement) }\end{array}$} & \multirow[b]{2}{*}{$\begin{array}{l}\text { Daytime natural } \\
\text { ventilation } \\
\text { (system control) }\end{array}$} & \multirow[b]{2}{*}{$\begin{array}{l}\text { Night } \\
\text { purge } \\
\text { (thermal } \\
\text { mass) }\end{array}$} & \multirow{2}{*}{\multicolumn{2}{|c|}{$\begin{array}{l}\text { HVAC System } \\
\text { Under-floor } \\
\text { air } \\
\text { distribution }\end{array}$}} & \multirow[b]{2}{*}{$\begin{array}{l}\text { High-effeciency } \\
\& \\
\text { energy-saving } \\
\text { equipments } \\
\text { (chiller/fans/pump/ } \\
\text { air economizer } \\
\text { /heat recovery) } \\
\end{array}$} & \multirow[b]{2}{*}{$\begin{array}{l}\text { Ground-source } \\
\text { heat pump }\end{array}$} & \multicolumn{3}{|c|}{ Renewable Energy } \\
\hline & $\begin{array}{c}\text { Maximum } \\
\text { utilization } \\
\text { of } \\
\text { daylighting }\end{array}$ & $\begin{array}{c}\text { High-efficiency } \\
\text { lighting system } \\
\text { (low power } \\
\text { density) }\end{array}$ & $\begin{array}{c}\text { Lighting } \\
\text { control } \\
\text { (occupancy } \\
\text { or } \\
\text { dimming } \\
\text { controlling) }\end{array}$ & & & & & & & & PV & $\begin{array}{c}\text { Solar } \\
\text { thermal }\end{array}$ & $\begin{array}{l}\text { Wind } \\
\text { turbine }\end{array}$ \\
\hline $0-1$ & & & 33 & & & & 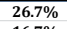 & & $73.3 \%$ & & $66.7 \%$ & $46.7 \%$ & $33.3 \%$ \\
\hline $100-200$ & 70 & & & & & & $16.7 \%$ & & & & $33.3 \%$ & & \\
\hline$>200$ & $83.3 \%$ & $16.7 \%$ & $16.7 \%$ & $66.7 \%$ & $58.3 \%$ & $16.7 \%$ & $33.3 \%$ & $8.3 \%$ & $58.3 \%$ & $8.3 \%$ & $41.7 \%$ & $8.3 \%$ & $0.0 \%$ \\
\hline
\end{tabular}

As highlighted in red in Table 4, some technologies - high-efficiency lighting systems, lighting control technology, and ground-source heat pumps - appear to have a somewhat positive correlation to low site EUI. Where the percentages of these three technologies are high, the EUIs are low. This correlation suggests the possibility that these measures might be responsible for or contribute strongly to low energy consumption in buildings. However, in the corresponding columns for these three technologies in Table 3, some buildings that have these three technologies use more energy than other buildings that do not have them. So, overall, the application percentages show a wide range of scatter for all the technologies, and it is challenging to pick out a group of technologies that only appear in buildings with low EUIs. We conclude that a higher application rate for some technologies only indicates that those technologies are widely used in HPBs but does not correlate with actual energy use.

The scatter in the results above as well as the discrepancies among EUIs of buildings sharing similar technology configurations suggests that stacking or simply adding more technologies to a building does not lead to low energy use. Integrated design and operation are likely key to integrating all the technologies in a building to achieve designed energy performance.

\subsubsection{Climate vs. Technologies}

It is widely recognized that the suitability and performance of some technologies depend heavily on the climate. We looked at the application and performance of technologies in different climate zones to analyze the influence of climate on building performance.

For each building in our study, we collected all information relative to efficient technologies, EUI, and climate zone into a matrix, shown in Table 5. We used the same four climates as described in Section 3.2, and EUIs were sorted from minimum to maximum in each climate zone. Table 5 clearly shows the relationship between technology and energy performance. 
Table 5. Application of efficient technologies in the four climate zones

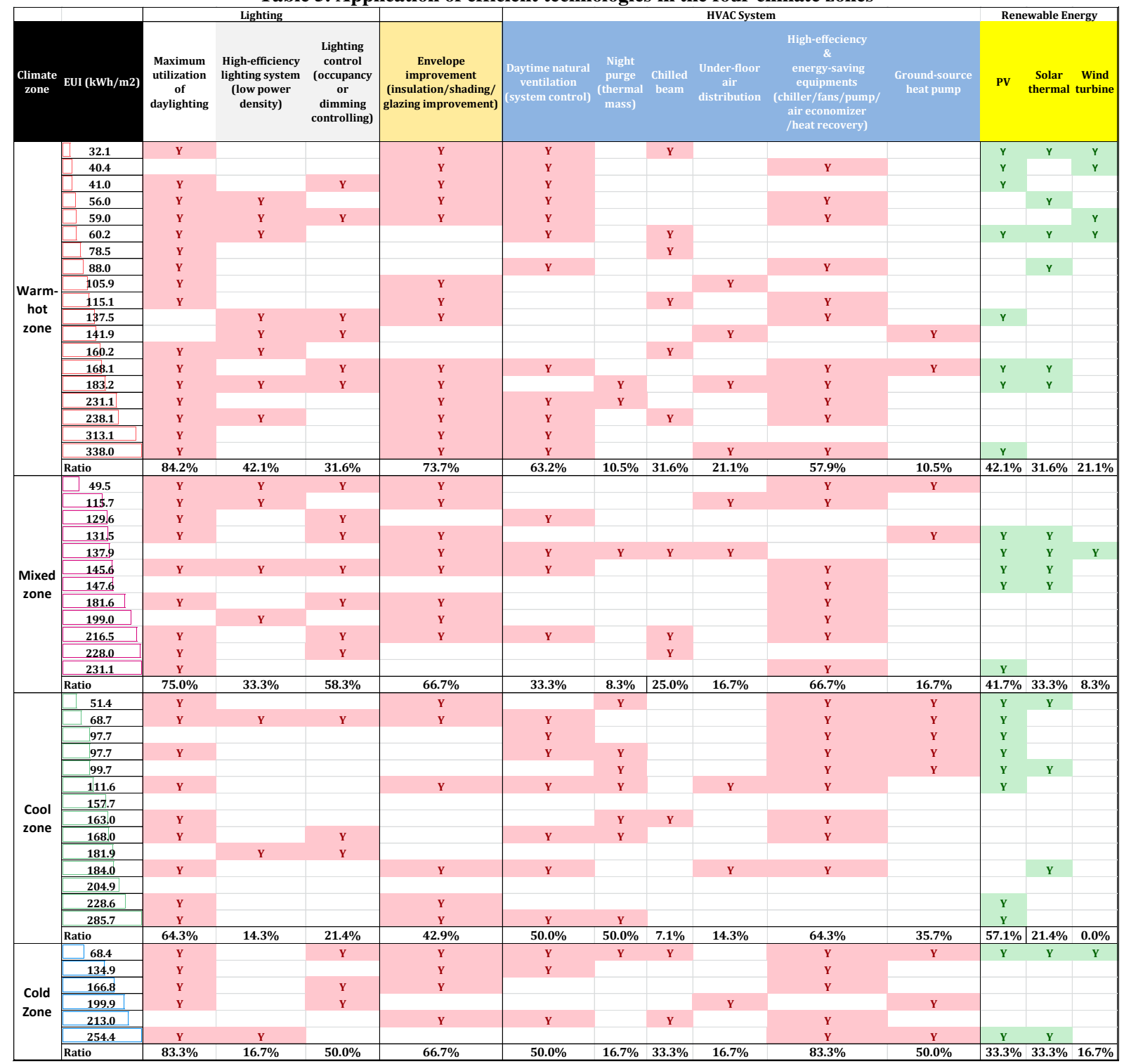

In Table 5 we see that daylighting, envelope improvements, and high-efficiency equipment are the dominant efficiency technologies in all climates. In addition, buildings in the warm and hot as well as mixed zone tend to employ more lighting-related measures. In conjunction with the wide application of daylighting in buildings in these zones, this trend could be attributed partly to abundant sunshine in these climates.

Additionally, with no need for space heating in these two climate zones, lighting is relatively dominant in building energy profiles. This means lighting-related technologies are important for saving energy in buildings in these climates. Therefore, a high rate of application of lighting-related technologies is expected in these zones.

Diurnal natural ventilation, as a common passive approach to offset the energy needed to cool the indoor environment, is widely applied in all climate zones. In the warm and hot zone, because of high energy consumption for space cooling, natural ventilation is usually the first and most basic strategy employed in an 
HPB. Therefore, it is not surprising that $63.2 \%$ of buildings in the warm and hot climate use natural ventilation. For the cool and cold zones, air temperature is very beneficial resource for space cooling. Because there are few or no cooling loads in these areas, natural ventilation can sometimes meet a building's entire space cooling requirement without the need for any energy-driven cooling strategies. Therefore, it is reasonable that $50 \%$ of buildings in the cool and cold zones have natural ventilation.

In the renewable energy category, solar photovoltaic (PV) technology is common in buildings in all regions, indicating wide acceptance of PV in the field of HPB design. Thermal solar, which requires a minimum level of solar radiation, is more common in the warm and hot as well as mixed zones. The relatively low percentage of wind turbines suggests barriers to widespread adoption of this technology. Overall in the renewable energy category, solar PV appears to be the first choice. A noteworthy observation about renewable energy technologies is that their application is concentrated in low-EUI buildings in the warm and hot zone. It is conceivable that buildings with low EUIs are more likely to achieve net-zero energy, with deployment of small scale renewable energy technology.

\subsubsection{Building size in relation to Technologies}

As indicated in Section 3.3, a building's floor area was implicitly linked to energy consumption, especially in buildings smaller than $5,000 \mathrm{~m}^{2}$. We explored the correlations between building size and use of technologies in an effort to uncover the reason for that link. Table 6 shows the percentage of study buildings containing each technology in the five categories of building size that we established.

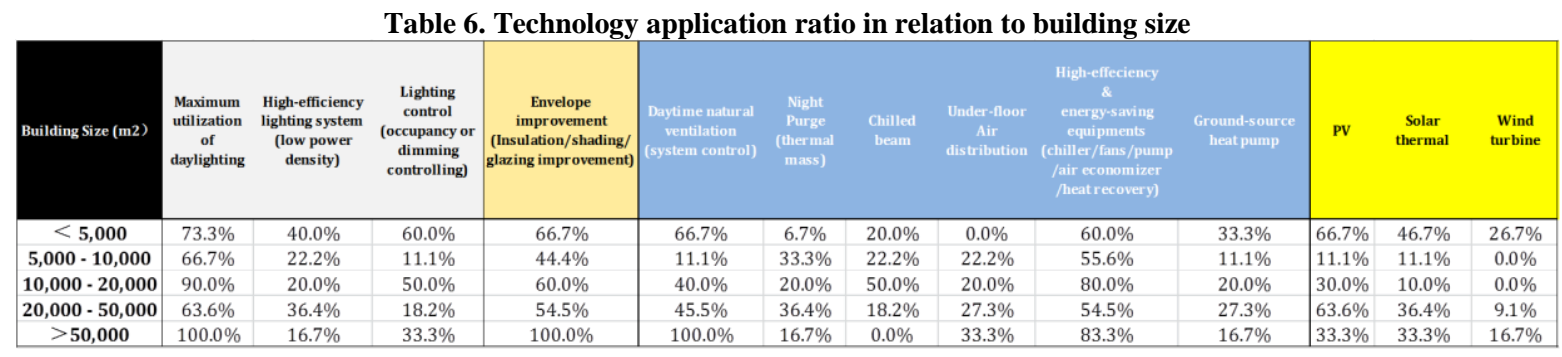

It is not surprising to see, in Table 6, that the top three technologies identified previously (daylighting, envelope improvements, and efficient HVAC equipment) are widespread in buildings of all sizes. In small buildings (floor area less than $5,000 \mathrm{~m}^{2}$ ), we can see that three additional technologies are frequently found: high-efficiency lighting, lighting controls, and natural ventilation. Among lighting technologies, in addition to the prevailing use of daylighting, high-efficiency lighting systems and lighting controls are widely deployed. Small buildings usually have relatively larger perimeter areas compared to those of large buildings with deep floor plans. Lighting needs in perimeter-area workspaces can usually be met with daylighting during the daytime. Therefore, the combination of daylighting and well-designed artificial lighting for nighttime hours can 
contribute significantly to total energy savings in these buildings. In addition, the simple structure and shallow depth of small buildings make the application and control of natural ventilation feasible for replacing or reducing the need for mechanical space cooling. This is the primary reason for the popularity of natural ventilation in small buildings.

Renewable-energy technologies are also widely applied in small buildings, $46.7 \%$ and $66.7 \%$, for solar thermal and solar PV, respectively. The high percentage of low EUIs in the group of small buildings along with the extensive application of renewable energy appear to give small buildings high potential to use net-zero energy, and, as noted in [4], small buildings are prevalent in the current portfolio of net-zero energy buildings. Practically speaking, it is much easier for small buildings located on spacious sites to install renewable-energy technologies. However, deployment of renewable energy technologies in large buildings should not be neglected even though it might be constrained by the complexity of the structure of large buildings as well as the dense development of the sites on which they are located. The data show that some renewable energy technologies are deployed in large buildings even if at relatively small scales. In general, although the deployment of renewable energy is more extensive in small buildings, the application of these technologies is not necessarily linked to building size.

\subsection{Discussion}

Although the selected 51 buildings are all office type buildings, their functions can be diverse. Large buildings tend to have more equipment and complex uses, e.g. data centers and mixed-use spaces, which complicates their energy use profiles. Only two buildings in our study have the detailed data on the functionality, so excluding the special function-related energy use before calculating the EUI for comparison is not possible. This is a good topic for future research assuming more detailed data are available.

There are other influencing factors, such as number of occupants and operation hours, that can affect the energy performance of buildings. Due to the lack of such information for the 51 buildings, no analysis is done to look at the impact of these factors. This is another area for future research.

More detailed and accurate benchmarking tools are available to compare energy use of buildings, but they require much more data which are not readily available for the 51 studied buildings. For example, the US EPA Energy Star Portfolio Manager, the most widely acknowledged benchmarking system, needs as many as 27 types of physical characteristics of a building in order to normalize the EUI for a more impartial peer comparison [44, 45]. 
Recalling the initial target and the five questions raised in the first section, however, we would like to explore the explicit relationship between the factors we studied and the actual EUI, rather than looking at the normalized EUI for benchmarking. This would be more constructive and helpful for the design and operation of a HPB.

The functional characteristics, such as the occupant density and the operation hours, are deemed to have significant effect on energy use. The analysis on the building size in section 3.3 also implied so. In fact, they are more than simply design criteria to meet. In the actual design and operation, design team may sometimes actively take these two factors into account to motivate occupant's positive energy behavior and better operation strategies in buildings. In light of this, it is meaningful to investigate them in the context of design and operation to improve the understanding of HPB.

\section{Detailed analysis of building performance}

As described in Section 1, building energy performance is affected by not only climate, building size, and efficient technologies but also by human behavior and building O\&M, which can have significant influence. Because research on occupant behavior and O\&M requires detailed information about energy use as well as occupant activities and building operations, we analyzed the influence of these two factors for only two of our 51 buildings for which we had detailed energy use and operations records. The case buildings are the headquarters of the Institute of Building Research (IBR) in Shenzhen, China and the headquarters of California State Teachers' Retirement System (CalSTRS) in Sacramento, California, USA.

\subsection{Shenzhen Institute of Building Research Headquarters}

The Shenzhen IBR building was designed and constructed as a high-performance demonstration building. Shenzhen IBR, an innovative architecture corporation, used the design of its new headquarters building as an opportunity to explore HPB design and operational approaches. After analyzing more than 100 sustainable technologies and strategies, IBR incorporated 40, delivering a building that stands out as exemplary in the field of HPBs.

The 12-story IBR building is located in Shenzhen, a coastal city located in Southern China between Guangzhou and Hong Kong. The building is approximately 45 meters tall and 30 meters deep with a total floor area of approximately $20,000 \mathrm{~m}^{2}\left(215,278 \mathrm{ft}^{2}\right)$. The building accommodates 350 to 450 occupants. According to the ASHRAE climate zones, Shenzhen is in a subtropical climate with monthly average dry-bulb temperature 
ranging between $14.9{ }^{\circ} \mathrm{C}$ and $28.6{ }^{\circ} \mathrm{C}$. A noteworthy characteristic of the climate is that winter temperatures are, on average, greater than $12{ }^{\circ} \mathrm{C}$; therefore, space heating is not required by code. Research reports that residents in this area tend to open windows for fresh air in winter [46]. The Shenzhen IBR building was first occupied in 2008, and more than two years' of measured energy use data were available as of October, 2012 [46, 47].

The aggregate site EUI of the IBR building from November, 2011 to October, 2012 was $57.3 \mathrm{kWh} / \mathrm{m}^{2}$ [46]. In Figure 5, the IBR building's EUI is the seventh lowest among the study buildings. Diamond et al.'s study of the IBR building [47] established an energy performance benchmark based 57 large Shenzhen office buildings whose function, operating hours, and occupant density were similar to those of the IBR building. The IBR headquarters' energy performance was one of the lowest compared to this benchmark. Figure 11 (a) shows that the major end uses in the IBR building are lighting, plugs, and air conditioning. Figure 11 (b) illustrates the energy profile of a comparable building with similar function in the same locality. The mean EUI of the peer building stock in Diamond et al.'s study was $103 \mathrm{kWh} / \mathrm{m}^{2}$, and the median EUI was $96 \mathrm{kWh} / \mathrm{m}^{2}$. Based on these values, we use one building (referred to the PEER Building A hereafter) from Diamond et al.'s study, which has an EUI of $85 \mathrm{kWh} / \mathrm{m}^{2}$, to represent the average energy performance of Shenzhen office buildings that are comparable to the IBR building. The IBR building uses 30\% less energy than the PEER Building A. The majority of the energy savings are in space cooling and lighting and plugs, which were innovative design highlights of the IBR building.

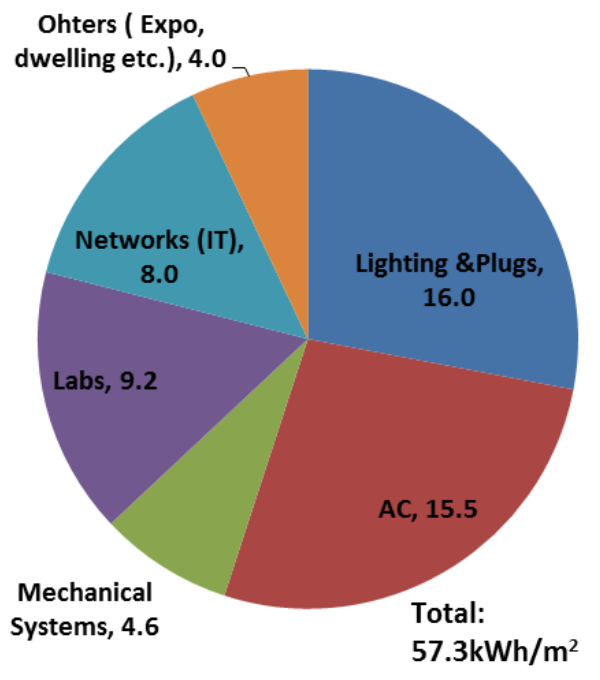

(a) Breakdown of IBR building's energy profile profile

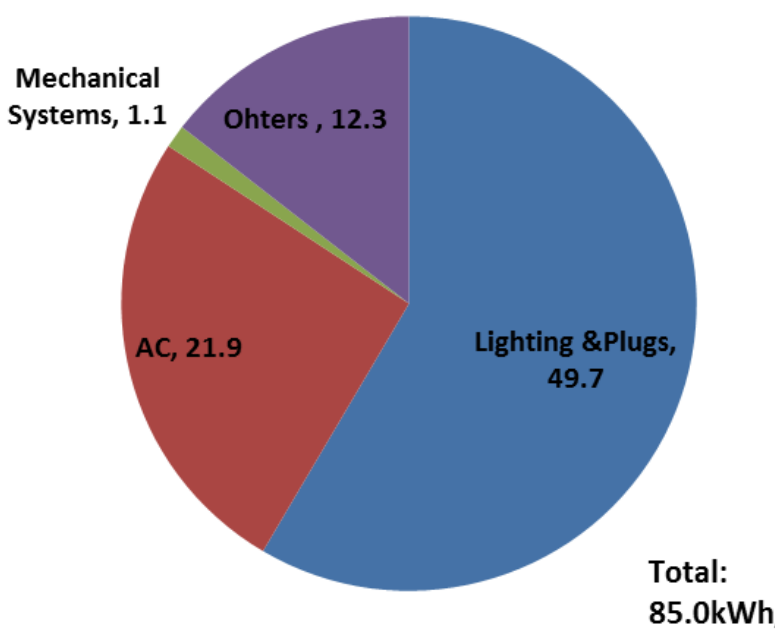

(b) Breakdown of the PEER Building A's energy

Figure 11. Energy consumption breakdown for IBR Building and the PEER Building A

The IBR building's design and operation extensively leverage the benefits of natural ventilation and daylighting to reduce the use of mechanical cooling and artificial lighting. The design team took occupant 
behavior and local cultural habits into account. People in Shenzhen place high value on fresh air and have a relatively broader indoor thermal acceptable range than is typical. In response to this, the designers left all control of the IBR building's windows to the discretion of occupants. In addition, high-inertia thermal mass and solar shading systems were designed to shield the building from solar gain and to capture night cooling. The floor plan allows adequate natural ventilation during regular office hours. Space cooling is provided by mechanical air conditioning (AC) and natural ventilation (NV), depending on the time of the year. AC can be used to provide cooling from April 22 to October 21; during the remainder of the year, the building relies on NV only. During the AC period, AC is only on from 8 am to $6 \mathrm{pm}$ on weekdays when the forecast daily maximum temperature is higher than $27{ }^{\circ} \mathrm{C}$. Otherwise, the building manager turns off the $\mathrm{AC}$ and relies on natural ventilation. During the NV portion of the year, the only AC used during regular operations is via split units for the information technology portion of the building and for some special-function rooms. During the period from November, 2011 to October, 2012, the mechanical cooling ran for a total of 108 days [46] whereas in typical office buildings in Shenzhen during the same period, mechanical cooling ran for 140 days. Looking at the monthly breakdowns of energy use in the IBR building and in peer building A, shown in Figure 12, we see that the majority of the AC energy consumption in the IBR building was from May to October while peer building A shows significant AC energy use from April to October. Quantitatively, the annual site EUI of the AC in the IBR building is $15.5 \mathrm{kWh} / \mathrm{m}^{2}$ compared to $21.9 \mathrm{kWh} / \mathrm{m}^{2}$ in peer building A, indicating that the use of NV in the IBR building helped reduce space cooling energy use.

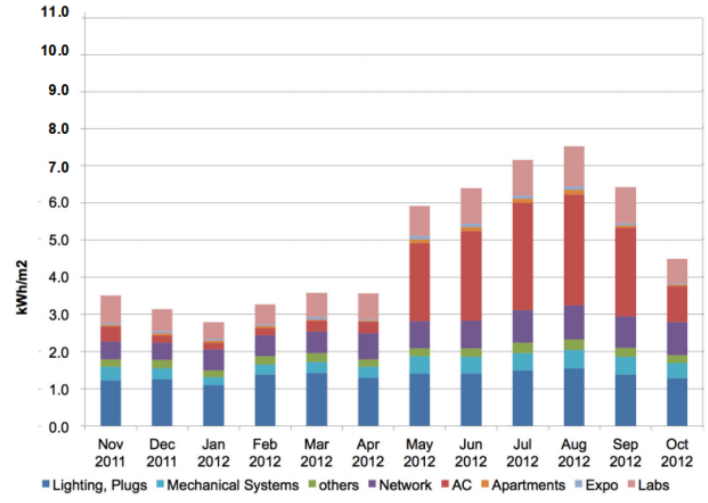

(a) Breakdown of IBR building energy profile

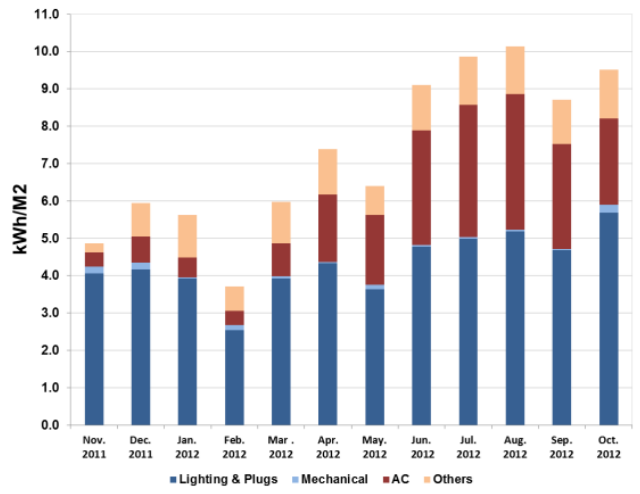

(b) Breakdown of peer building A energy profile

Figure 12. Monthly breakdown of the IBR Building and the PEER Building A site EUIs

The monthly breakdown shows that the largest part of the IBR building's energy savings is in the category of lighting and plugs. To reduce energy consumed by artificial lighting and plug loads, which usually account for the largest portion of energy use in office buildings, the IBR building took full advantage of energy-saving 
occupant behaviors. All artificial lighting was designed to be manually controlled by building staff. In work areas, task lights can be operated independently for each row of desks. Because all workspaces are located in the building's perimeter zones and have sufficient daylighting, the IBR staff is encouraged to turn lights on only when necessary and to turn them off when not in use. Staff was also trained to use lighting in the building's public areas as little as possible. All these efforts reduced lighting energy use significantly in the IBR headquarters compared to lighting energy use in comparable buildings. Figure 13 illustrates an on-site investigation of artificial lighting use in a $720-\mathrm{m}^{2}$ office space of the IBR Building during work hours of a fiveday week in April, 2012. The weather conditions during this investigation were mostly cloudy and rainy. Nonetheless, we pinpointed periods of low lighting use. The red circles indicate lunch times when staff deliberately switched off most lights; these are the periods of lowest lighting energy use during each day. After lunch, the lighting energy use did not show a sharp rise but instead gradually increased with the time until the peak from 4 to $6 \mathrm{pm}$. On some days, like Thursday and Friday, the lighting energy use continued to go down even after lunch time. This trend implies that daylighting was indeed replacing artificial lighting during regular working hours, even during cloudy conditions. Furthermore, the total wattage used over the course of investigation never exceeded $70 \%$ of the total installed wattage even on cloudy days.

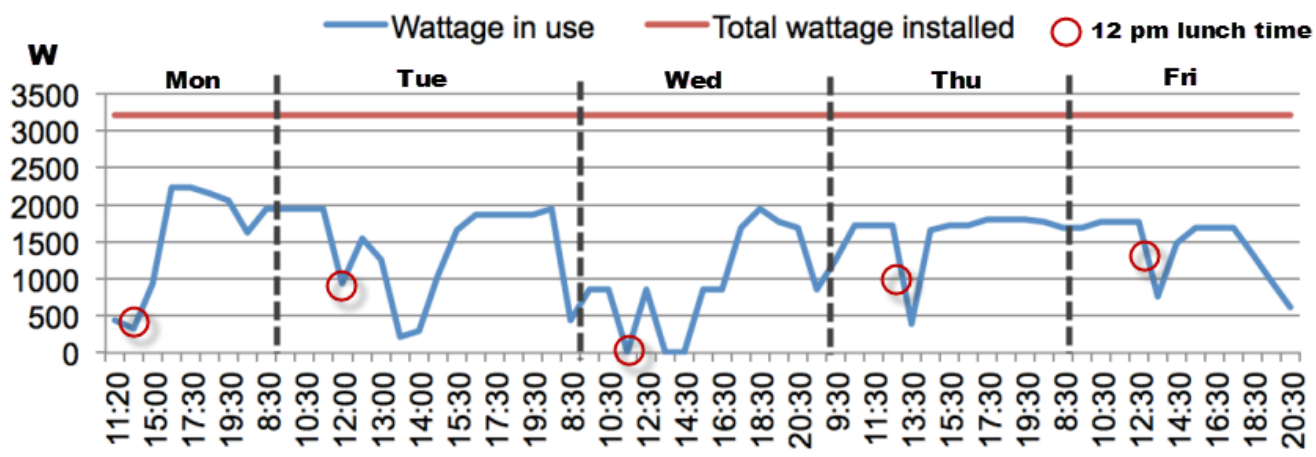

Figure 13. On-site investigation of artificial lighting use in the IBR Building [44]

The IBR building demonstrates that effective integration of occupant behavior in building design and operation and use of natural ventilation and daylighting to replace mechanical cooling and artificial lighting can save significant energy in office buildings.

\subsection{California State Teachers' Retirement System Headquarters}

The Headquarters of the California State Teachers' Retirement System (CalSTRS), is an 18-story, Class A office building in Sacramento, California. Constructed in 2009, the CalSTRS building comprises a 13-floor office tower atop five floors of cafés, parking, and public access areas. The five floors of parking, etc. are about $4,273 \mathrm{~m}^{2}$, and the tower is $29,728 \mathrm{~m}^{2}$, for a total occupied floor area of $34,373 \mathrm{~m}^{2}$. Aside from the regular office 
space, CalSTRS headquarters houses a $408-\mathrm{m}^{2}$ data center on the fourth floor, equipped with a computer room air condition, uninterruptible power supply, and data servers.

CalSTRS, which owns and operates its headquarters building, did not set an ambitious green building goal at the outset; initially, the design team was required to achieve only LEED-NC Silver Certification. But by prioritizing occupant satisfaction and good O\&M practices, the CalSTRS building managed to obtain LEED-NC Gold certification, LEED-EBOM Platinum certification, and high scores of 94 (in 2011) and 92 (in 2012) in the EnergyStar rating system, for its excellent post-occupancy performance $[48,49]$.

The site EUI in the first year of occupancy was $198 \mathrm{kWh} / \mathrm{m}^{2}$. Excluding the energy use for the public service areas, the office tower has an EUI of $142 \mathrm{kWh} / \mathrm{m}^{2}$ based on data from March, 2012 to February, 2013. Figure 14 shows that the CalSTRS building's energy-intensive data center accounts for nearly half of the total energy consumption of the building. However, the CalSTRS building is $12 \%$ more efficient than its peer buildings in the California Commercial End-Use Survey (CEUS) building stock. ${ }^{1}$ Specifically, the CalSTRS building's HVAC energy use is approximately half that of the average CEUS building [50].

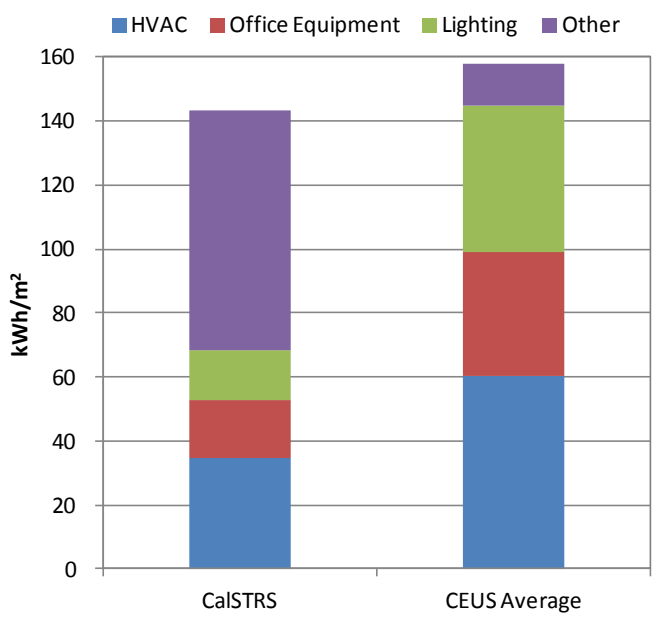

(a) Breakdown of whole building

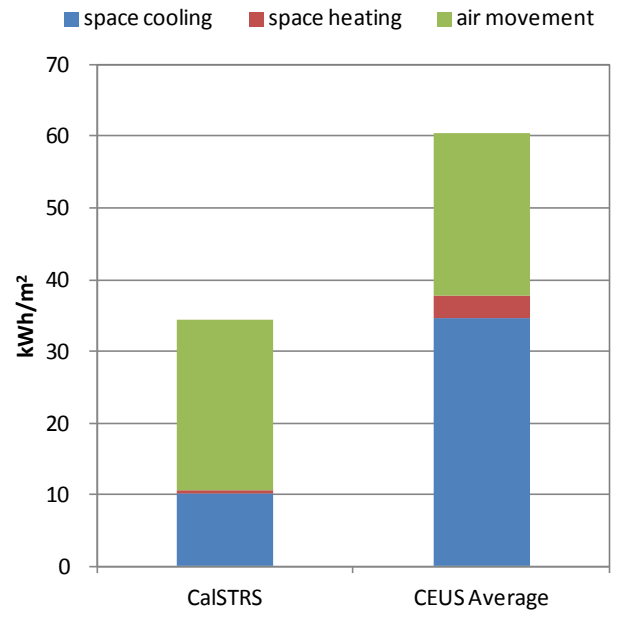

(b) Breakdown of HVAC

Figure 14. Benchmarking CalSTRS headquarters energy use

CalSTRS headquarters' outstanding energy performance is a result of high-quality integrated design combined with good building O\&M practices. The building does not actually have more building technologies deployed. Highlights of energy-saving technologies and design strategies are: maximum daylighting, dimmable artificial lighting control system, UFAD with occupant-adjustable diffusers, water-source heat pump for cooling and heating of the public areas, and two chillers with variable-speed compressors for the office tower. The building's configuration does not stand out from that of other comparable buildings (see row 25 of Table 3 , EUI

\footnotetext{
${ }^{1}$ In Figure 14 (a), the designation "Other" for the CalSTRS building includes not only elevators, domestic hot water pumps, and other similar uses, but also the high-energy-consumption data center.
} 
of $141.9 \mathrm{kWh} / \mathrm{m}^{2}$ ). However, the highly integrated design, which is partly a result of the fact that the building is owner occupied, sets it apart from the others and accounts for the energy performance. Coordinated by a sustainable consulting firm, the design team included all major project stakeholders: owner/developer, architect, engineer, landscape architect, contractor, and operations team. The design team valued occupant behavior, postoccupancy operations, and maintenance as important elements of their sustainable design. From the very beginning, the occupants' preferences and building operator's advice were extensively considered and incorporated into the design process. Input from the occupants and building operator gave the design team the opportunity to resolve many accessibility and functionality issues that could have hindered O\&M. Moreover, the sustainable consulting firm assumed the role of commissioning agent for the building, and a thorough commissioning was completed in early 2011. The building has a computer-based maintenance and management system as part of service by Facility 360. Preventive and scheduled maintenance ensure reliable operation of building systems. Other recent initiatives to increase energy savings include:

- Automating the west shaft supply air damper to direct the main air supply to load areas

- $\quad$ Resetting the main air-handling unit pressure set point

- $\quad$ Resetting the chilled water supply temperature

- $\quad$ Resetting the under-floor air damper set points

- Adjusting fan terminal unit airflow set points to match local load conditions

- Modifying cooling tower operation on cooler days to minimize fan power

The CalSTRS building case study demonstrates that integrated design and best practices in building O\&M are critical elements in successful low-energy buildings.

\section{Summary and Conclusions}

Our portfolio analysis and case studies revealed that actual energy use in U.S., EU, and China-Pacific region office buildings that are certified as high performing varies significantly, and nearly half of the buildings fell short of the ASHRAE Standard 90.1-2004 energy target. Thus, looking at average performance masks the reality that a large number of HPBs are falling short of their energy-saving potential. Our results indicate that certifications of HPBs do not necessarily correspond to actual energy performance and raise questions about the current practice of using simulated rather than actual performance as the basis for certifications. The global scope of our study along with the fact that no specific region or country demonstrated consistently betterperforming HPBs suggests that ensuring the actual energy-saving performance of HPBs is a global challenge. 
Our analysis of the influence of climate, building size, efficient technologies, occupant behavior, and O\&M in HPBs indicates that no single factor is decisive in determining a building's actual energy performance and that increasing the number of efficient technologies does not improve energy performance. However, occupant behavior and O\&M can play significant positive roles in realizing building energy savings.

Energy performance of buildings can be driven by other factors, such as the operation hours, the number of occupants and the building functions (space use type: mixed use, data centers, commercial cooking).

Unfortunately such information is only available for a very limited number of the selected buildings, so any impact analysis of these factors is not possible in this study. However it is a good topic for future building performance studies.

Our conclusion that no single factor determines building energy performance means that the exact factors that drive building energy use remain obscure; therefore, strategies for saving energy should take account of all elements that might affect actual energy use in a particular building. For example, climate may affect cooling and heating loads, use of daylighting, and design and operation of natural ventilation; the arrangement of the building's functions and the behavior of its occupants may influence the building's operational schedule and thus the energy use; the presence of high-efficiency equipment and the employment of good O\&M practices will directly reduce the building's energy use. An integrated design approach that takes account of all of the above factors offers the greatest potential for producing a building whose actual performance is energy efficient. The findings of our study should help architects, engineers, operators, and policy makers to improve the design and operation of HPBs as well as the degree to which rating HPB rating systems accurately reflect actual building performance.

\section{Acknowledgments}

This work was sponsored by the U.S. Department of Energy (Contract No. DE-AC02-05CH11231) and the China Ministry of Housing and Urban - Rural Development and the Ministry of Science \& Technology (Grant No. 2010DFA72740-02) under the U.S.-China Clean Energy Research Center for Building Energy Efficiency. Data and information on the CalSTRS building were provided by David Hill of Jones Lang LaSalle. Some data on Chinese buildings were provided by Qi Zhang of Tsinghua University, China.

\section{Glossary}

AC air conditioning

ASHRAE American Society of Heating, Refrigeration, and Air-conditioning Engineers 


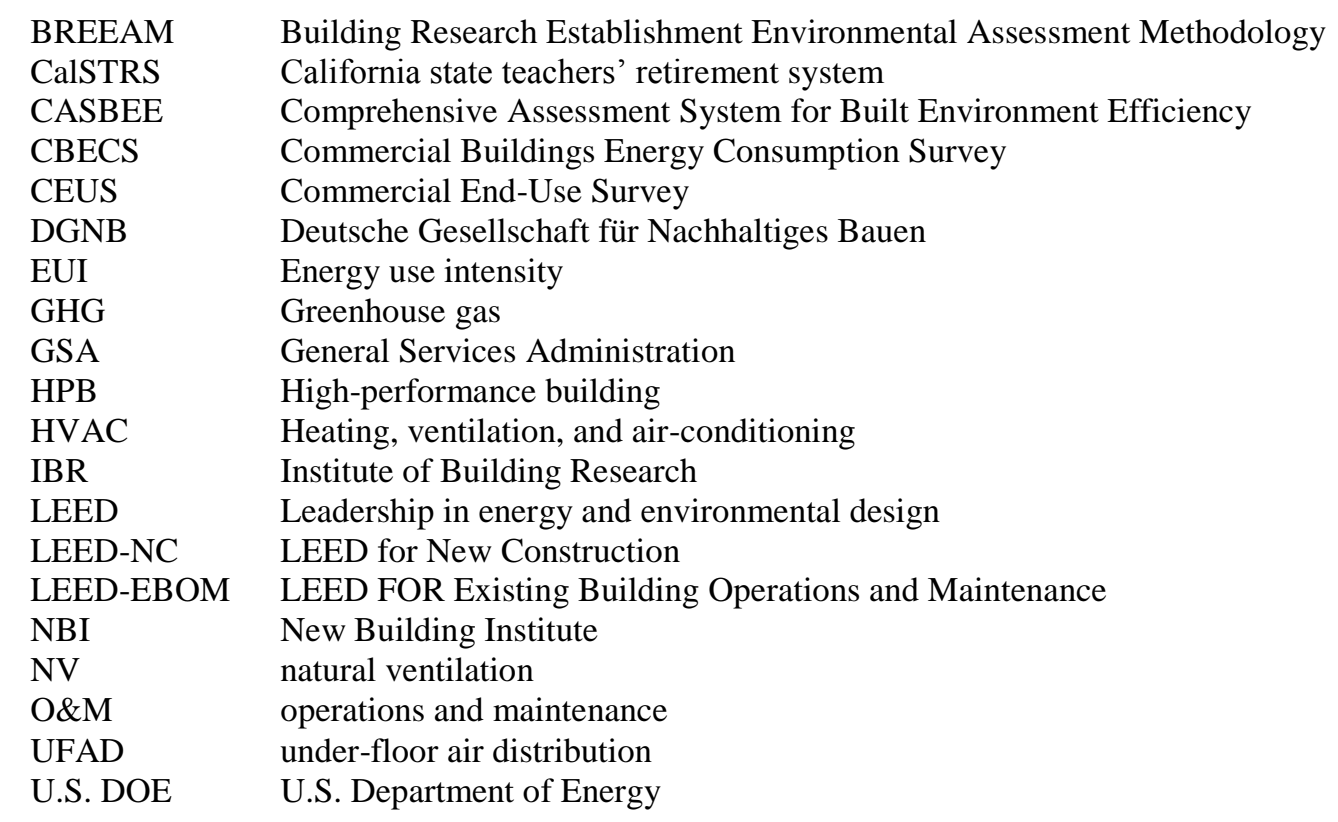




\section{References}

[1]. U.S. Department of Energy. Energy Efficiency Trends in Residential and Commercial Buildings; 2010.

[2]. Brown RE, Koomey JG. Electricity use in California: past trends and present usage patterns. Energy Policy 2003; 31:849-64.

[3]. International Energy Agency. World energy outlook 2010; 2010.

[4]. New Building Institute (NBI). Getting to Zero 2012 Status Update: A First Look at the Costs and Features of Zero Energy Commercial Buildings; 2012.

[5]. Li DHW, Yang L, Lam JC. Zero energy buildings and sustainable development implications - A review. Energy 2013; 54:1-10.

[6]. Industrial Economics, Incorporated. Analysis of Green Building Programs; 2005.

[7]. Legislative Research Commission, Kentucky. Energy-efficient Building Design and Construction Practices. Research Memorandum No. 503; 2009.

[8]. Rainwater B, Martin C. Local leaders in sustainability: a study of green building programs in our nation's communities: American Institute of Architects; 2008.

[9]. Peterman A, Kourula A, Levitt R. A roadmap for navigating voluntary and mandated programs for building energy efficiency. Energy Policy 2012; 43:415-26.

[10]. Thilakaratne R, Lew V. Is LEED Leading Asia?: an Analysis of Global Adaptation and Trends. Procedia Engineering 2011; 21:1136-44.

[11]. LEED | U.S. Green Building Council. U.S. Green Building Council.< http://www.usgbc.org/leed/rating-systems $>$

[12]. Directory of LEED NC buildings. U.S Green Building Council. < http://www.usgbc.org/projects >

[13]. Xiao J. Study on Post Occupancy Evaluation of Green Public buildings: Tsinghua University; 2013.

[14]. Fowler KM, Rauch EM, Henderson JW, Kora AR. Re-assessing green building performance: A post occupancy evaluation of 22 GSA buildings: Pacific Northwest National Laboratory 2010.

[15]. Heerwagen J, Zagreus L. The human factors of sustainable building design: post occupancy evaluation of the Philip Merrill Environmental Center. 2005.

[16]. Turner C. LEED building performance in the Cascadia Region: A post occupancy evaluation report. 2006.

[17]. Torcellini PA, Deru M, Griffith B, Long N, Pless S, Judkoff R, et al. Lessons learned from field 
evaluation of six high-performance buildings: National Renewable Energy Laboratory; 2006.

[18]. Diamond R. Evaluating the energy performance of the first generation of LEED-certified commercial buildings. 2011.

[19]. Turner C, Frankel M. Energy performance of LEED for new construction buildings: New Buildings Institute; 2008.

[20]. GSA Public Buildings Service. Office of Applied Science. Assessing Green Building Performance: a post occupancy evaluation of 12 GSA buildings (White paper); 2008.

[21]. Fowler KM, Rauch EM. Assessing Green Building Performance: A Post Occupancy Evaluation of 12 GSA Buildings (Full report): Pacific Northwest National Laboratory; 2008.

[22]. Donlad Bren School of Environmental Science \& Management, University of California, Santa Barbara. Green Buildings in the U.S and China: Bridging the Energy Performance Gap; 2012.

[23]. Scofield JH. Do LEED-certified buildings save energy? Not really.... Energy and Buildings 2009; 41:1386-90.

[24]. Scofield JH, Oberlin O. A re-examination of the NBI LEED building energy consumption study. International Energy Program Evaluation Conference, Portland, OR2009.

[25]. Newsham GR, Mancini S, Birt BJ. Do LEED-certified buildings save energy? Yes, but.... Energy and Buildings 2009; 41:897-905.

[26]. Navarro M. Some Building Not Living Up to Green Label. The New York Times: The New York Times Company; 2009.

[27]. Barbarino A. BOA Tower an Energy Guzzler Despite LEED-Platinum: New Republic. In: Barbarino A, editor.2013.

[28]. Alter L. LEED-bashing: Is the Bank of America Building really a "toxic tower"? 2013.

[29]. BREEAM: the world's leading design and assessment method for sustainable buildings. < http://www.breeam.org/ >

[30]. CASBEE, Comprehensive Assessment System for Built Environment Efficiency. < http://www.ibec.or.jp/CASBEE/english/ >

[31]. DGNB System - Sustainable and green building. < http://www.dgnb-system.de/en/ >

[32]. China Green Building Evaluation Label. < http://www.cngb.org.cn/ >

[33]. Hong T, Chou SK, Bong TY. Building simulation: an overview of developments and information 
sources. Building and Environment 2000; 35(4):347-361.

[34]. Lin HW, Hong T. On Variations of Space-heating Energy Use in Office Buildings. Applied Energy 2013; 111:515-528.

[35]. Yudelson J, Meyer U, Kwok AG. The World's Greenest Buildings: Promise Versus Performance in Sustainable Design: Routledge; 2013.

[36]. China Green Building. Beijing, China: China Architecture \& Building Press; 2013.

[37]. International Energy Agency, Energy Conservation in Buildings and Community Systems. Annex 53: Total Energy Use in Buildings - Analysis and Evaluation Methods. 2013.

[38]. U.S. Energy Information Administration. Commercial Buildings Energy Consumption Survey (CBECS). 2003.

[39]. ASHRAE Standard 90.1-2004: Energy Standard for Buildings Except Low-Rise Residential Buildings. 2004.

[40]. ASHRAE Standard 90.1-2010: Energy Standard for Buildings Except Low-Rise Residential Buildings. 2010.

[41]. U.S. Department of Energy. Achieving the 30\% Goal: Energy and Cost Savings Analysis of ASHRAE Standard 90.1-2010; 2011.

[42]. LEED for Existing Buildings - US Green Building Council. U.S. Green Building Council. $\langle\underline{\text { http://www.usgbc.org/ebom }}>$

[43]. Hong T, Chang WK, Lin HW. A fresh look at weather impact on peak electricity demand and energy use of buildings using 30-year actual weather data. Applied Energy 2013; 111:333-50.

[44]. U.S. Environmental Protection Agency. Energy Star Performance Rating - Technical Methodology; 2011

[45]. U.S. Environmental Protection Agency. Energy Star Performance Rating - Technical Methodology for Office, Bank/Financial Institution, and Courthouse; 2007

[46]. DAMIENS J. Using passive design for offices in a subtropical climate: a case study in Shenzhen. Beijing: Tsinghua University; 2013.

[47]. Diamond RC, Ye Q, Feng W, Yan T, Mao H, Li Y, et al. Sustainable Building in China - A Green Leap Forward? Buildings 2013; 3:639-58.

[48]. The Center for the Built Environment at the University of California, Berkeley. Case study of CalSTRS 
headquarters, Final Report; 2011.

[49]. U.S. Environmental Protection Agency. Energy Star Labeled Buildings \& Plants. <http://www.energystar.gov/index.cfm?fuseaction=labeled_buildings.showProfile\&profile_id=1018512>

4 [50]. Hong T, Yang L, Hill D, Feng W. Data and analytics to inform energy retrofit of high performance buildings, Applied Energy 2014; 126: 90-106.

6 